\title{
Literatura na televisão: história, memória e biografia
}

Ana Maria Camargo Figueiredo

Professora doutora em Ciências da Comunicação pela ECA/USP

e professora e pesquisadora do Centro Interdisciplinar de Pesquisa

da Faculdade de Comunicação Social Cásper Libero.

E-mail: anacfigueiredo@uol.com.br

A rede Globo vinha procurando uma estratégia para conquistar o telespectador do horário das 22 horas, mas a telenovela, gênero que funcionava como pilar de sustentação da televisão brasileira naquele momento, não alcançava mais os patamares dos $60 \%$ e $70 \%$ de audiência da década de 1970. Em 1982, com a minissérie Lampião e Maria Bonita ${ }^{1}$, o novo formato se apresentou como uma alternativa. Francisco Sandrin, diretor de produção da emissora, afirmava: "A espinha dorsal da programação da Globo é a novela, mas não se pode espremer uma laranja até secar. Com as minisséries, estamos criando alternativas de programação"

Além de surgir como formato alternativo à telenovela, a minissérie parecia talhada a captar o interesse do telespectador para o horário mais tardio, conforme pesquisa de audiência feita pela emissora em São Paulo e no Rio de Janeiro. Por não se tratar de uma obra aberta como a novela e por haver mais controle sobre a produção, a minissérie aborda temáticas delicadas e obedece a critérios de rigor até mesmo nos anúncios e comerciais. Os atores também têm avaliado positivamente suas atuações nas produções de minisséries. Lucélia Santos, protagonista de Meu Destino é Pecar", considera: "Na novela, você entra com cara de mocinha, vira freira, depois prostituta, mata o irmão e ainda é absolvida. Já na minissérie, o ator sabe perfeitamente onde está e para onde vai seu personagem, e por isso pode se esmerar em sua carreira psicológica" ${ }^{4}$. O mesmo ponto de vista foi defendido, mais tarde, pela atriz Dina Sfat, a Eleusina de Rabo de Saia ${ }^{5}$ : "A minissérie é a saída da televisão. Ninguém agüenta mais a novela. São seis meses em cima de um código que não pode ser alterado, andando em círculos" .

Essa nova forma de fazer dramaturgia na televisão surge, então, como um campo privilegiado para os experimentos e como saída para os desafios da produção ficcional brasileira. Desta idéia compartilhavam outras redes tele-

1. De Aguinaldo Silva e Doc Comparato, com direção de Paulo Afonso Grizolli e Luís Antônio Piá, abr./maio 1982. Recebeu medalha de ouro no Festival Internacional de Cinema e TV de Nova York.

2. VEJA. São Paulo: Editora Abril, p. 95, 11 abr. 1984.

3. De Euclydes Marinho, com direção de Ademar Guerra e Denise Saraceni, maio/jun. 1984.

4. VEJA. São Paulo: Editora Abril, p. 95, 11 abr. 1984.

5. De Walter George Durst, José Antonio de Souza e Tairone Feitosa, com direção de Walter Avancini, out./nov. 1984.

6. VEJA. São Paulo: Editora Abril, p. 57, 24 out. 1984. 
visivas, como a Manchete que, àquela altura, não havia produzido telenovelas, mas já contava com três projetos de minissérie: A Marquesa de Santos, de Wilson Aguiar, Viver a Vida, de Manuel Carlos, e Santa Marta Fabril, adaptada por Geraldo Vietri. O diretor da Manchete à época, Zevi Ghivelder, confirmava o bom conceito desfrutado pela minissérie: "Ela está aí para ser inventada, não sofre as intempéries da novela, em que a personagem do capítulo 1 é um crápula, no capítulo 20 vira santo e no 50 se torna diabo de novo"7.

O que diferencia a minissérie da telenovela, garantindo à primeira mais qualidade de produção e mais envolvimento do telespectador?

Em primeiro lugar, sua caracterização como obra fechada, completamente escrita quando se iniciam as gravações, o que implica uma unidade e uma visão de conjunto do tema. Essa particularidade a aproxima da produção cinematográfica e lhe garante maior qualidade estética. Quanto à sua estrutura textual, Renata Pallotini afirma que, mesmo que a minissérie possa apresentar-se como uma telenovela curta, ela "desenvolve, na verdade, uma trama básica, à qual se acrescentam incidentes menores [...], procura conter [a história] num plot, num conflito básico, numa linha central de ação bem definida, não comportando a diversidade de linhas de ação da telenovela, às vezes só consolidada depois que ela está em andamento". ${ }^{8}$ Enquanto a minissérie se caracteriza pelo drama e pela trama alinhavada por meio da ação da personagem, com coerência do começo ao fim, a telenovela, ao contrário, é uma obra aberta, extensa e redundante.

\section{LITERATURA E TELEFICÇÃO}

A literatura, eterna matéria-prima do teatro e do cinema, é também a base das minisséries que levam ao telespectador histórias do nosso cotidiano e, algumas delas, um pouco de uma história mais geral e coletiva. Algumas relembram a Independência do Brasil, outras enfocam o período republicano e o jogo de poder da aristocracia rural do País, outras, ainda, abordam a industrialização no País, quando imigrantes chegaram para participar da construção da nação.

Poderíamos dizer que há uma revivescência da história do Brasil, uma atualização da memória na telinha, que se coloca como foco de resistência ${ }^{9}$ (um ponto de vista crítico quanto à realidade dada) a uma visão globalizante e elitista quer da própria história oficial, quer dos meios de comunicação de massa. Foco de resistência porque, ao lado da presença da elite, representada pela aristocracia, pela nobreza ou pelos empresários capitalistas, há sempre espaço para a figura do povo - o jagunço, o escravo, o revolucionário.

É nesse contexto que a televisão ocupa um lugar fundamental, mediando culturas, fazendo interagir diferentes personagens, eliminando fronteiras, mas, ao mesmo tempo, reforçando e até mesmo promovendo nossa identidade. Os meios de comunicação, particularmente a televisão, acabam por espetacularizar nossas inseguranças e nossos medos, trazendo para o telespectador confinado em sua casa uma possibilidade de elaborá-los através da ficção. 
A partir dessas idéias é que se estrutura o presente trabalho. Como a produção ficcional televisiva pode se revelar como foco de resistência às tendências de um projeto espetacular e autoritário de TV? De que maneira nos apresenta a história pátria como um acontecimento povoado de contradições e de protagonistas nem sempre oficiais? De que maneira amplia nossa visão histórica e funda uma memória mais complexa e menos linear?

Essas questões são produtos de uma pesquisa em revistas e jornais da década de 1980, período de redemocratização do País, quando pensá-lo criticamente era, mais que nunca, uma exigência de nossa cidadania. Qual foi a contribuição das minisséries para esse momento reflexivo? A partir da literatura e de sua adaptação para um novo formato inovador e vanguardista, abre-se um caminho para se falar de nós em toda sua complexidade e - por que não - em sua ambigüidade.

Para proposta de leitura das minisséries da década de 1980, escolhemos seis adaptações literárias - Anarquistas, Graças a Deus (Globo), de Zélia Gattai, adaptada por Walter George Durst; Meu Destino é Pecar (Globo), texto adaptado de Nelson Rodrigues; Marquesa de Santos (Manchete), de Paulo Setúbal, adaptado por Wilson Aguiar Filho; A Máfia no Brasil (Globo), de Edson Magalhães, adaptado por Leopoldo Serra, Afonso Grisolli e Roberto Faria; Rabo de Saia (Globo), de José Condé, adaptado por Walter George Durst, José Antonio de Souza e Tairone Feitosa; e Santa Marta Fabril (Manchete), de Abílio Pereira de Almeida, adaptado por Geraldo Vietri - as quais foram estudadas, analisadas e comparadas através de material de arquivo em texto e imagem. Completou esse estudo a leitura das obras originais e da mídia impressa da época, especialmente da seção Televisão, espaço de divulgação, de comentários e de avaliações da produção televisiva brasileira. Trouxemos para esta análise a visão crítica de sua época.

Ao fim deste extenso trabalho analítico que mostrou a procedência de nossa hipótese - de que as minisséries são espaços de releitura de nossa história, em uma proposta dialética e múltipla -, escolhemos como estudo de caso para ser aqui abordado a minissérie Anarquistas, Graças a Deus. Escolha que se justifica pela revisão que realiza de nossa história, principalmente a do começo do século XX, quando o Brasil ingressa na modernidade; assim como pela reconhecida qualidade estética, marca de um novo momento da produção televisiva do Brasil.

\section{A DÉCADA DE 1980 - ENTRE INFERNO E PARAÍSO}

A década de 1980 se anuncia como um tempo de crise, pois, apesar de terem-se mostrado inviáveis as ditaduras existentes na década anterior no mundo ainda subdesenvolvido, o alto grau de internacionalização da economia e da cultura parece ameaçar nossa identidade de país periférico, miserável, analfabeto e desigual. Como entrar no processo de globalização sem perder nossas características e contornos? 
Por outro lado, foi uma década marcada por conquistas políticas e por movimentos sociais que emergem com força, lutando pela cidadania do homem brasileiro, que procura ocupar o espaço público do qual tinha sido excluído.

$\mathrm{O}$ ano de 1984 assistiu a vários movimentos, entre eles ao da campanha das Diretas Já, culminando com a derrota da emenda Dante de Oliveira, a qual propunha eleições diretas para a presidência da República; às greves dos professores das universidades federais, dos médicos residentes do País e dos bóias-frias da região de Bebedouro, interior de São Paulo. Foi ainda o ano em que os partidos se rearranjaram e disputaram a presidência e a vice-presidência da República no Colégio Eleitoral.

Foi um ano com avanços e retrocessos. Avanços, se considerarmos toda a mobilização da população civil respondendo ao Estado, comprometido com a burguesia nacional e internacional; retrocessos, na medida em que o povo foi submetido a uma inflação de $223,54 \%$ ao ano e a uma taxa de desemprego que atingiu 28,4\%. A insatisfação popular era evidente e, conseqüentemente, a impopularidade do Governo era cada vez maior, como comprovaram as passeatas e os saques a supermercados, "sintoma claro de esgotamento de suas possibilidades e da esperança em qualquer medida efetiva das autoridades para resolver o problema do desemprego" 10 .

A indústria cultural desenvolveu-se, fazendo-se cada vez mais presente e eficiente, sustentada por uma ideologia autoritária que pretendia a sintese de uma "cultura híbrida"

É nesse cenário que a ficção televisiva, num modelo novo e de vanguarda, possibilitou a releitura de nossa história, em um movimento de reflexão e de formação identitária.

10. RODRIGUES, S. Marly. A década de 80: o Brasil quando a multidão voltou às praças. 2. ed. São Paulo: Ática, 1994. p. 11. (Série Princípios).

11. Sobre cultura híbrida, ver CANCLINI, Nestor. Culturas híbridas. São Paulo: Edusp, 1997.

12. GATTAI, Zélia. Anarquistas, graças a Deus. 22. ed. Rio de Janeiro: Record, 1995.

\section{LITERATURA NA TELEVISÃO: BIOGRAFIA, FICÇÃO E HISTÓRIA}

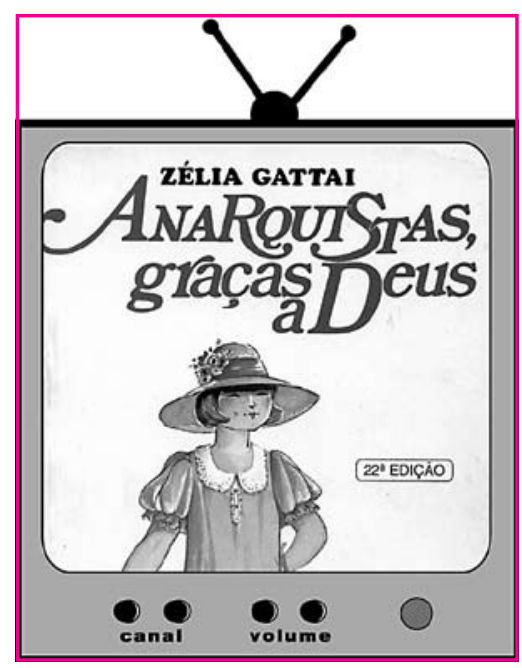

Gattai: o resgate do cotidiano de imigrantes italianos.
O telespectador, no mês de maio de 1984, teve a oportunidade de encontrar-se com a obra da autora Zélia Gattai, Anarquistas, Graças a Deus ${ }^{12}$, adaptada por Walter Georg Durst e dirigida por Walter Avancini. O livro foi lançado em 1979 e, quando foi ao ar em imagens, já alcançava a sétima edição. Trata-se da história biográfica da família Gattai que chegou ao Brasil em fevereiro de 1890, junto de outros imigrantes, para morar em uma colônia socialista experimental, a Colônia Cecília, organizada por um grupo anarquista, os Cárdias.

A colônia era apoiada por D. Pedro II, mas, com a proclamação da República e a deportação do imperador, teve que contar apenas com seus 
membros, encontrando enormes dificuldades. Dois anos depois, a colônia se desfez. Outra família, Da Col, com a qual os Gattai se uniram pelo casamento de seus filhos, teve outra experiência no Brasil. Integraram-se na plantação de café de São Paulo até o momento em que Eugênio Da Col se rebelou contra o dono do latifúndio, a quem vira chicotear um negro. Depois disso, Eugênio vai para a capital em busca de trabalho, empregando-se na serraria de um conterrâneo.

No livro de Gattai, as histórias dessas famílias se inserem na história pátria, resgatando o cotidiano de imigrantes italianos na cidade de São Paulo, nas décadas de 1920 e 1930, tendo Dona Angelina Gattai como protagonista, uma mulher anarquista que aprecia a literatura clássica, o cinema, as reuniões políticas, e que gosta de socorrer os infortunados e alfabetizá-los.

É por meio das memórias de uma criança, a própria autora, que tomamos conhecimento do cotidiano das famílias italianas e das experiências vividas na revolução de 1924, quando Ernesto, pai da autora, se posiciona contra o governo. Em conseqüência disso, a família fica sem dinheiro, sem trabalho e sem comida.

Em outro momento da narrativa, em 1937, a autora, já adolescente, nos encaminha para outro acontecimento da história do País, o Estado Novo, quando Ernesto é preso e considerado um comunista perigoso. Por trás do cotidiano dos Gattai, das festas, dos folguedos de rua, do cinema, das relações familiares, estão presentes os grupos anarquistas, antifascistas, que tentam se organizar e, violentamente, responder à violência dos grupos dominantes.

Essa história é transposta para o vídeo com muito capricho, contando com a colaboração da emissora italiana Rettequatro, que, entusiasmada com o projeto, ofereceu filmes de época sobre a partida dos imigrantes italianos em direção ao Brasil. O diretor teve então o cuidado de juntar esses documentários de época a imagens novas, em uma elaboração poética e criativa. O telespectador assiste a cenas da São Paulo antiga, integradas à história, acompanhadas de diálogos que fazem interagir personagens históricos e ficcionais. Conforme opinião dos artistas que protagonizam a minissérie - Débora Duarte como Angelina, Ney Latorraca como Ernesto e a menina Daniele Rodrigues (a Narizinho da série infantil Sítio do Pica-pau Amarelo) no papel de Zélia -, este foi um dos mais meticulosos trabalhos da televisão brasileira. Walter Georg Durst evidenciou o lado lírico do dia-a-dia das famílias italianas e, a partir do casamento de Ernesto e Angelina, centrou a ação no sonho da Colônia Cecília.

Sob a direção de Avancini, Anarquistas, Graças a Deus prende o telespectador não pela continuidade dramática, mas pelo interesse que cada unidade do relato cria a partir de uma concepção única e integradora.

Por essa estratégia poética de adaptação da obra literária para a televisão, a família Gattai integra-se à história da construção de São Paulo, como parte dos imigrantes italianos, como participantes das greves operárias, ou mesmo como cidadãos comuns que vivem o cotidiano da época - passeiam de bonde e assistem a corridas de automóvel. 
Assim, pela união entre cenografia, vestuário, linguajar e sotaque, a família Gattai sai da memória da menina e entra na história do País e com ela colide, confronta-se e interage. Apresenta-se como o imigrante, o estranho na sociedade brasileira, mas também como o subalterno, o inimigo político, o grupo social antagônico - os anarquistas. Graças à maestria da autora, do adaptador, do diretor e dos atores, a história não ficou reduzida ao cenário, às informações paralelas e à moral da história; faz parte da estrutura narrativa e é o eixo que dá sentido ao drama particular, pessoal e privado.

A revisitação de tais obras literárias pela televisão, no ano de 1984, aponta um caminho adotado pelos produtores de ficção no formato minissérie, como forma de resistir à espetacularização do mundo globalizado da década de 1980, espetacularização essa que é reforçada, em grande parte, pelos meios de comunicação. Essa mescla entre ficção, história e biografia, atualizada pela teledramaturgia, aparece como uma revisão do nacional no projeto internacionalizante da época. Num momento em que a nossa história perde a unidade, estilhaça-se e se encurta, recriar esses momentos ganha, como propusemos no início deste texto, as dimensões de um foco de resistência.

Resumo: A autora analisa o fenômeno das minisséries na rede Globo durante o ano de 1984, em especial Anarquistas, Graças a Deus, adaptação do romance de Zélia Gattai, identificado com o gênero memória, que recria historicamente alguns períodos da realidade brasileira, através dos dramas do cotidiano de homens e mulheres. Revela-se, por trás disso, uma história maior, que determina as formas da violência que intermedeiam as relações sociais. A revisitação de tais obras literárias pela televisão, especialmente no ano de 1984, aponta um caminho adotado pelos produtores de ficção no formato minissérie, como forma de resistir à espetacularização do mundo globalizado da década de 1980. Essa mescla entre ficção, história e biografia, atualizada pela teledramaturgia, aparece como uma revisão do nacional no projeto internacionalizante da época.

Palavras-chave: minissérie, literatura, teleficção, cotidiano, história, movimento anarquista, Zélia Gattai, Walter George Durst.
Abstract: The author analyzes the phenomenon of miniseries in Globo network along the year of 1984, with emphasis in Anarquistas, Graças a Deus, adaptation of Zélia Gattai's novel, identified as genre memoir, that recreates historically some periods of Brazilian reality through men's and women's daily dramas, revealing behind them a greater history that determines the shapes of the violence that intermediates the social relations. The revisit of such literary pieces by television, especially in the year of 1984, indicates the path adopted by the producers of fiction in miniseries format as a way to resist to spectacularization of the global world in the decade of 80 . This mixture of fiction, history and biography, updated by TV dramaturgy, appears as a revision of the national in the internationalizating project of that time.

Keywords: miniseries, literature, telefiction, quotidian, history, anarchist movement, Zélia Gattai, Walter George Durst. 